Provided for non-commercial research and education use. Not for reproduction, distribution or commercial use.

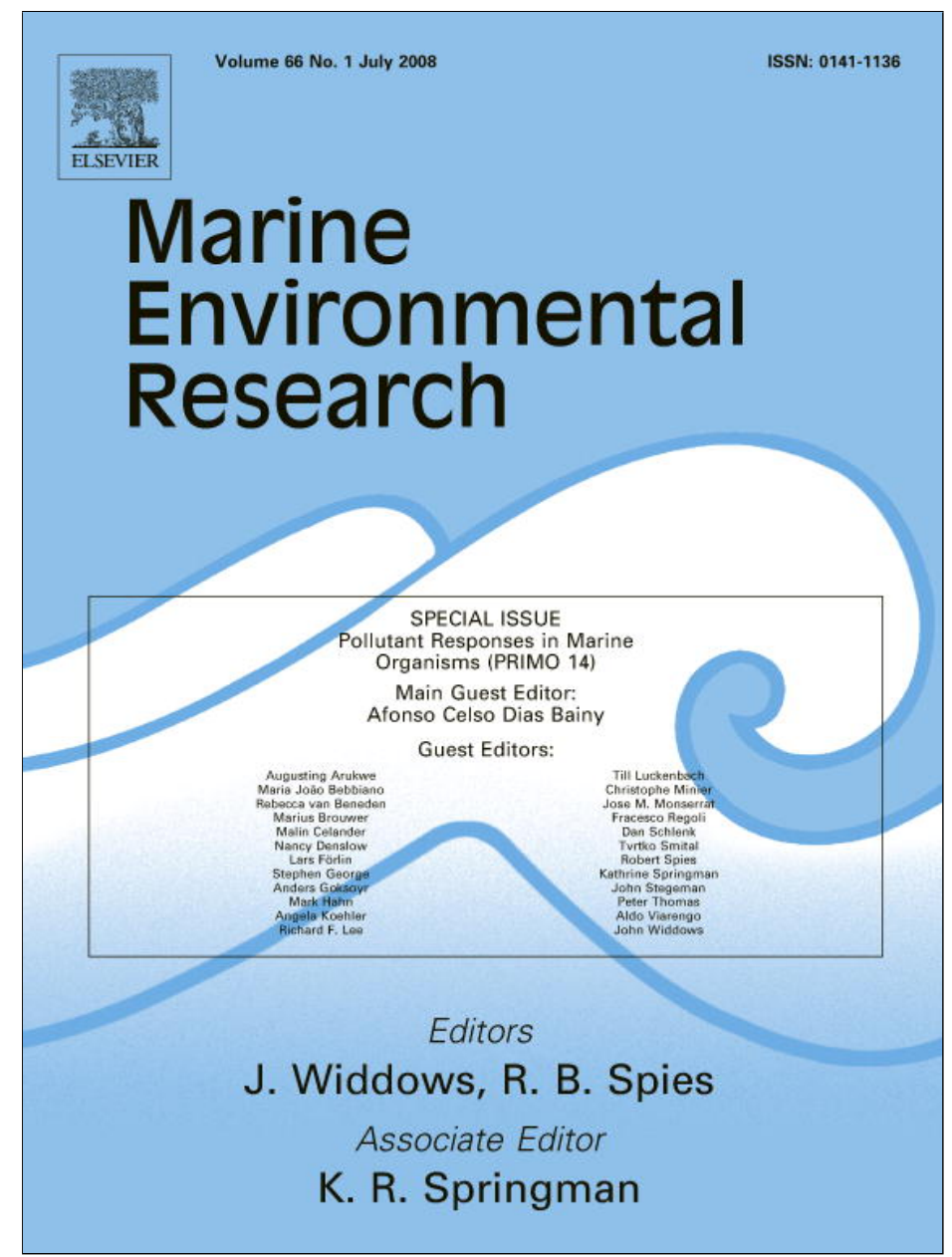

This article appeared in a journal published by Elsevier. The attached copy is furnished to the author for internal non-commercial research and education use, including for instruction at the authors institution and sharing with colleagues.

Other uses, including reproduction and distribution, or selling or licensing copies, or posting to personal, institutional or third party websites are prohibited.

In most cases authors are permitted to post their version of the article (e.g. in Word or Tex form) to their personal website or institutional repository. Authors requiring further information regarding Elsevier's archiving and manuscript policies are encouraged to visit:

http://www.elsevier.com/copyright 


\title{
The liver of wrasse - Morphology and function as a mirror of point source chemical impact
}

\author{
Katja Broeg*, Wiebke Kaiser, Sieglinde Bahns, Angela Koehler \\ Alfred Wegener Institute for Polar and Marine Research, 27570 Bremerhaven, Germany
}

\section{A R T I C L E I N F O}

\section{Keywords:}

Symphodus melops L.

Wrasse

Histopathology

Lisosomal membrane stability

$\mathrm{PAH}$

\begin{abstract}
A B S T R A C T
Corkwing wrasse (Symphodus melops L.), a protogynous, non-migratory lipfish species, living close to rocky shores was chosen as an indicator species for the monitoring of biological effects of contaminants. Fish were caught by local fisherman at the Norwegian west coast in fjord sites within the framework of the EU BEEP project. The sites represented different point source impacts of (I) copper (a former copper mine), (II) polycyclic aromatic hydrocarbons (PAHs, aluminium smelter discharge), (III) formaldehyde plus PAHs (kelp-factory and influence of the aluminium smelter). Livers of wrasse were studied for histopathological alterations and compared to healthy livers of fish from a reference location. Besides liver morphology, different functional and metabolic parameters were measured to link pathological alterations to functional disorders. The integrity of the lysosomal compartment was tested by the assessment of lysosomal membrane stability (lys), and the accumulation of neutral lipids and lipofuscin. Activity and intracellular localisation of the NADPH-producing enzymes in the liver were assessed histochemically and measured by computer-assisted image analysis. Histopathological alterations were most severe at the site impacted by formaldehyde and PAHs. These findings were associated with highest tumor prevalence, lowest membrane stabilities in hepatocytes and highest accumulation rates of lipofuscin in the liver. The activities of the NADPH-producing enzymes phosphogluconate dehydrogenase (PGDH) and glucose-6-phosphate dehydrogenase (G6PDH) were significantly lower compared to unimpacted reference fish. Histopathological alterations showed clear differences dependent on the input source. Potential links between specific contaminant impact and functional and morphological disorders are discussed.
\end{abstract}

(c) 2008 Elsevier Ltd. All rights reserved.
The integrity of liver of fish with respect to morphology and function, may serve as a direct and sensitive indicator for toxically-induced alterations reflecting the effects of anthropogenic impact on the health status of biological systems (Koehler, 1991; Hinton, 1994; Stentiford et al., 2003; Feist et al., 2004; Broeg et al., 2005). In the present multivariate study, a new indicator species, the corkwing wrasse (Symphodus melops) was tested for its potential to specify effects of clearly defined contaminant situations.

Livers were analysed for toxicopathic alterations by histopathology, lysosomal membrane stability (lys), storage disorders (neutral lipid accumulation), oxyradical reactions (lipofuscin formation), and by histochemistry of the main NADPH-producing enzymes, glucose-6-phosphate dehydrogenase (G6PDH) and phosphogluconate dehydrogenase (PGDH). NADPH is needed for biosynthesis, during biotransformation, oxyradical scavenging and elimination of xenobiotics.

Fish from four locations were sampled in the EU-project BEEP at the west coast of Norway. These locations were characterized by various point source impacts of copper, PAHs, and PAHs in combi-

\footnotetext{
* Corresponding author.

E-mail address: Katja.Broeg@awi.de (K. Broeg).
}

nation with formaldehyde (Andersen, 2002). In addition, a reference location was sampled. Data were analysed using the multivariate $k$-means analysis which allowed the integrated assessment of toxically-induced alterations at an individual level.

Corkwing wrasse between 13 and $21 \mathrm{~cm}$ were caught with fyke nets, measured and weighed. Subsequently fish were killed and one central part of the liver was excised and quick-frozen in liquid nitrogen for analysis of lysosomal membrane stability (Moore et al., 2004), activity of G6PDH and PGDH (Koehler and van Noorden, 1998) as well as neutral lipids (Bayliss, 1982) and Schmorl's lipofuscin (Moore et al., 2004). One adjacent liver piece of similar size was fixed in Baker's formalin and embedded in methacrylate. Sections were stained with Gills hematoxylin and eosin and periodic acid Schiff (PAS) for histopathology.

For the detailed quantification of the level of histopathological alterations, an evaluation sheet for wrasse liver was developed, based on the histopathological criteria developed for flatfish (Koehler, 2004; Feist et al., 2004). The diagnostic catalogue comprised 10 different categories of liver structures (liver tissue, liver cells, cell nucleus, cytoplasm of hepatocytes, bile ducts, pancreatic tissue, extracellular matrix, preneoplastic lesions, benign neoplasms, malignant neoplasms). Categories were graded according 
to the progressive stages of histopathological alterations to allow scoring of the observations. All measurements were carried out on each individual fish. Statistical analyses were performed using the STATISTICA software.

The data were analysed by the use of the multivariate $k$-means algorithm. This algorithm is a method to cluster objects based on their attributes into $k$ partitions of greatest possible distinction. It is attempted to identify the centers of natural clusters in the
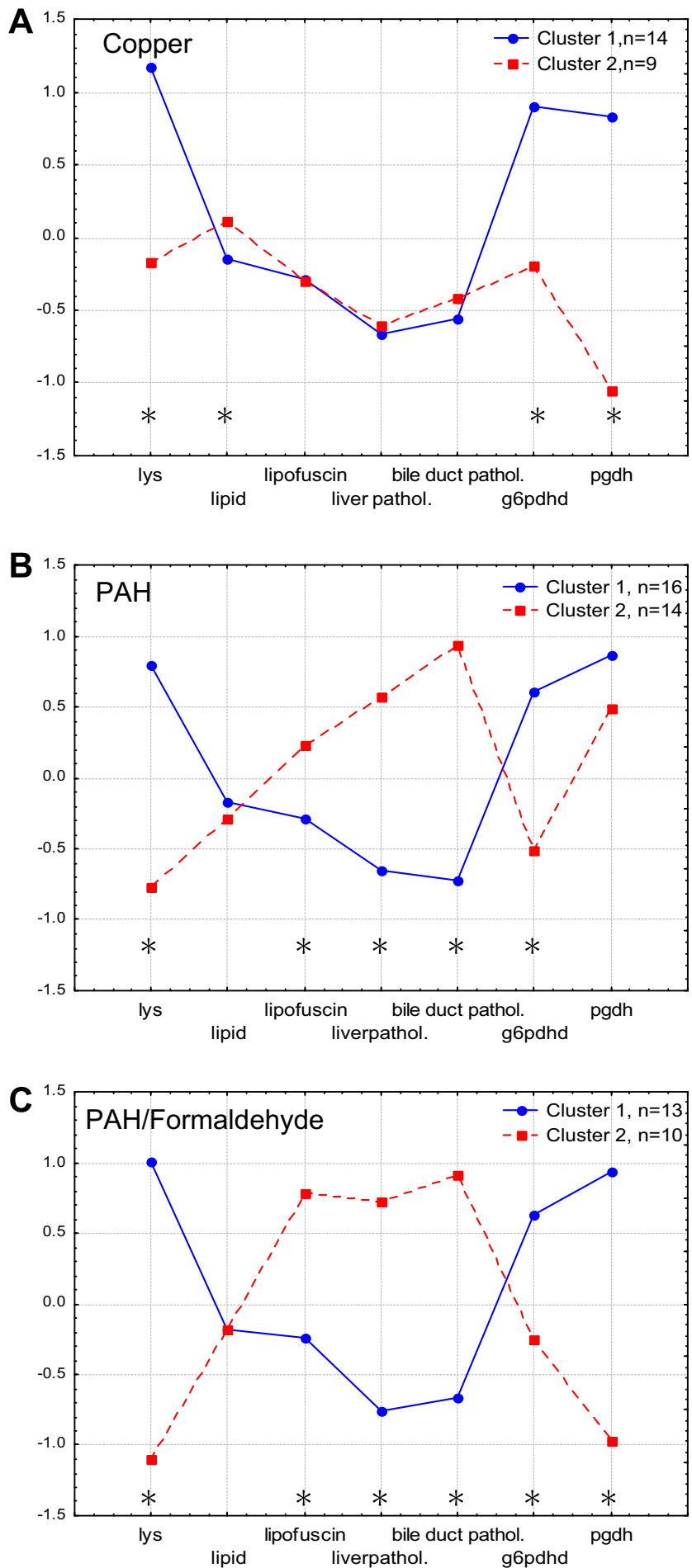

Fig. 1. Mean values of the $k$-means cluster analysis for (a) copper and reference, (b) $\mathrm{PAH}$ and reference, (c) $\mathrm{PAH} /$ formaldehyde and reference. Asterisk $=$ difference between the clusters is significant $(p<0.05)$. lys = lysosomal membrane stability, lipid = neutral lipid accumulation. data. Its main objective is to minimize total intra-cluster variance and maximise the between-cluster variance. Based on the present data of wrasse from each impact source in combination with the reference location two clusters were displayed.

The data showed one cluster of "healthy" wrasse which was characterised by high lysosomal membrane stability, low neutral lipid accumulation, low lipofuscin content, low histopathological alterations of liver tissue and bile ducts, and high G6PDH and PGDH activity (Fig. 1A-C, cluster 1). The second cluster of "impacted" wrasse showed the following differences at the copper site (Fig. 1A): significantly lower lysosomal membrane stability, significantly higher neutral lipid accumulation, and significantly decreased G6PDH and PGDH activity. Lipofuscin content as well as histopathological alterations of liver tissue were similar to the healthy cluster. At the metal location no preneoplastic and neoplastic lesions were observed. Wrasse from the PAH-impacted site showed the following effects (Fig. 1B, cluster 2): significantly lower lysosomal membrane stability and lower G6PDH activity, significantly enhanced histopathological alterations of liver tissue and bile ducts, significantly higher lipofuscin content, lower PGDH activity and higher neutral lipid accumulation. At the PAH-impacted location, $33 \%$ of the wrasse had preneoplastic and/or neoplastic liver lesions.

In wrasse caught at the site impacted with PAHs and formaldehyde (Fig. 1C, cluster 2) all parameters differed significantly from the healthy wrasse cluster with the exception of neutral lipid accumulation. At this station $70 \%$ of the wrasse had preneoplastic and/ or neoplastic liver lesions.

The present study showed specific patterns of histopathological alterations and functional disorders at different impact situations. Even though wrasse from the copper site showed lower lysosomal membrane stability, lipid accumulation and enzyme activities, pathological alterations were minor compared to fish from the sites impacted by $\mathrm{PAH}$ and $\mathrm{PAH} /$ formaldehyde. In the same metal exposed individuals, glycogen content in the livers was significantly higher than in all other wrasse, suggesting a successful adaptation to chronic high copper concentrations by (hypothesis I) increased energy supply for active copper elimination transport, (hypothesis II) formation of glycogen/protein macromolecules as copper binding sites.

The most striking pathological alteration at the $\mathrm{PAH}$ and $\mathrm{PAH} /$ formaldehyde location concerned the bile ducts. In general, bile ducts were more frequent in wrasse from these locations and bile duct epithelial cell proliferation was a common feature, indicating the formation of additional elimination portals of PAH metabolites from the liver. Taking together, the significantly decreased G6PDH and PGDH activities, the high amounts of lipofuscin in the livers of these fish, and the high tumor prevalence, especially in the PAH/ formaldehyde group, adaptative and compensatory capacities were obviously exhausted in these fish compared to metal exposed fish.

\section{References}

Andersen, O.K., 2002. BEEP WP4, Campaign 1, Norway 2001, site descriptions. In: Biological Effects of Environmental Pollution (BEEP) - EU-Project Meeting Athens, Greece.

Bayliss, O.B., 1982. In: Bancroft, J.D., Stevens, A. (Eds.), Theory and Practice of Histological Techniques. Churchill-Livingstone, Edinburgh, UK, pp. 217-241.

Broeg, K., Westernhagen, H.V., Zander, S., Körting, W., Koehler, A., 2005. Marine Pollution Bulletin 50, 495-503.

Feist, S., Lang, T., Stentiford, G.D., Koehler, A., 2004. ICES Techniques in Marine Environmental Sciences 38, 1-42.

Hinton, D.E., 1994. Aquatic Toxicology 24, 207-239.

Koehler, A, 2004. Aquatic Toxicology 70, 257-276.

Koehler, A., van Noorden, C.J.F., 1998. Aquatic Toxicology 40, 233-252.

Koehler, A., 1991. Comparative Biochemistry and Physiology (C) 100, 123-127.

Moore, M.N., Lowe, D., Koehler, A., 2004. ICES Techniques in Marine Environmental Sciences 36, 1-31.

Stentiford, G.D., Longshaw, M., Lyons, B.P., Jones, G., Green, M., Feist, S.W., 2003. Marine Environmental Research 55, 137-159. 